\title{
Reduction of Aeroacoustic Sound and Aerodynamic Drag using Porous Cover
}

\author{
Alexander M, Karthik K, Jeyakumar S
}

\begin{abstract}
The application of a porous media on square cylinders to reduce drag in cross-flow is an active research area. $B e$ that as it may, the related stream incited sound in the encompassing flow likewise experiences decrease, an angle which has gotten less consideration. This paper exhibits a numerical strategy for coupled streamlined and aero acoustic estimations for low Mach number flow current pass a square cylinder with permeable cover. Computations are performed at a subcritical Re of 54,800 using URANS technique and $F W$-H acoustic analogy. The cylinder without porous cover is subjected to an incoming flow is considered for validation against measurements. A significant drag reduction and sound reduction is observed with the presence of the porous layer. Comparisons are made among the modified cylinder and its unmodified counterpart.
\end{abstract}

Keywords: Aero acoustics, Aerodynamics, CFD, Passive control

\section{INTRODUCTION}

The interaction of high-speed flow past a solid body generates unsteady fluid dynamic loads, which in turn produces flow-induced noise, also called aeroacoustic sound (Rienstra and Sijtsma, 2018). Aerodynamic loads and the associated aero acoustic sound emitted from the bluff bodies are of concern for many applications, such as landing gear, automobiles, etc. (Kaviani and Nejat, 2017; Talotte, 2000; Vilela de Abreu et al., 2016). The numerical computation of aerodynamic and aero acoustic characteristics of rigid bluff bodies have received extensive attention (Kurbatskii and Mankbadi, 2004; Tam, 2006; Wang et al., 2006).

The development of aerodynamics led to streamlined structures which have decreased aerodynamic drag and self-induced noise in comparison to bluff bodies (Devinant et al., 2002; Moreau et al., 2014). But most structures encountered in the engineering applications are bluff bodies which include bridge piers, buildings, vehicles, chimneys, cooling towers, heat exchanger tubes, flame- holders, aircraft undercarriage during landing, pipelines and re-entry vehicles, to mention a few. Hence studying the aerodynamics and aero acoustics of bluff bodies, has been the field of interest of several numerical and experimental (Casalino and Jacob,

Revised Manuscript Received on December 5, 2019

* Correspondence Author

Alexander M, Ramesh Babu S, Department of Mechanical Engineering, Kalasalingam Academy of Research and Education, Krishnankoil, Srivilliputhur, Tamil Nadu 626128

Karthik K *, Department of Aeronautical Engineering, Kalasalingam Academy of Research and Education, Krishnankoil, Srivilliputhur, Tamil Nadu 626128.karthik@klu.ac.in

Jeyakumar S, Department of Aeronautical Engineering, Kalasalingam Academy of Research and Education, Krishnankoil, Srivilliputhur, Tamil Nadu 626128, sjeyakumar1974@gmail.com
2003; Cox et al., 1998; Gloerfelt et al., 2005; Guo et al., 2016; Inoue and Hatakeyama, 2002; Karthik et al., 2018a; Khalighi et al., 2010; King and Pfizenmaier, 2009; Moreau and Doolan, 2013). From the literature survey, it is observed that most of the analysis is concentrated on circular cylinders and a few reported investigations are found on the study of aerodynamic drag and flow-induced noise on flows over the square cylinder (Chauhan et al., 2018; King and Pfizenmaier, 2009; Latorre Iglesias et al., 2016; Purohit et al., 2014; Samion et al., 2016; Sukri Mat Ali et al., 2011).

Be that as it may, the related stream incited sound in the encompassing flow likewise experiences a decrease, an angle which has gotten less consideration. This paper exhibits a numerical strategy for coupled streamline and aero acoustic estimations for low Mach number wind current pass a square cylinder with permeable cover (Anirudh and Dhinakaran, 2018; Babu and Narasimhan, 2010; Bhattacharyya and Singh, 2011; Bruneau and Mortazavi, 2008, 2004; De and Ghosh, 1989; Geyer and Sarradj, 2016;

Jue, 2004; Liu et al., 2013; Naito and Fukagata, 2012; Rong et al., 2011; Salimi et al., 2015; Sueki et al., 2010; Yu et al., 2010; Zhao and Cheng, 2010). However, only a few studies have been performed for computing both the aerodynamic drag and aero acoustic sound of cylinders with a porous cover.

\section{GEOMETRY AND FLOW CONDITION}

In this work, a rigid square cylinder covered with porous media of porosity $(\varepsilon) 0.95$ is considered. All simulations in this paper are carried out at $\operatorname{Re}=\rho U D / \mu=54800$. The flow $\mathrm{Re}$ and the associated properties in this paper are consistent with the experimental values (Latorre Iglesias et al., 2016).

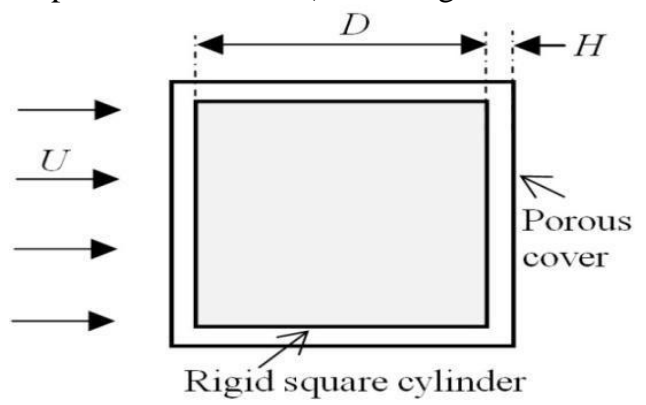

Figure 1: Definition sketch 


\section{COMPUTATIONAL METHODOLOGY}

The turbulent air flow field over the cylinder is computed by utilizing the two- dimensional URANS technique (Samion et al., 2016), where the numerical model simultaneously solves the mass and momentum conservation equations. Even though the flow field in this problem is $3 \mathrm{D}$ in nature, the $2 \mathrm{D}$ method can, however, obtain the significant aerodynamic and aero acoustic characteristics (Cox., 1998; Liu., 2015; Samion., 2016) at a cheap computational expense and is a more appropriate technique for a parametric study (Khorrami et al., 2007). The k- $\omega$ SST model (Menter, 1994; Wilcox, 2006) is employed to provide closure to the system of equations formed by URANS. The FVM with the QUICK (Leonard, 1979) is used for the spatial discretization, while a 1 st order discretization is utilized for transient discretization. The SIMPLE calculation is used for the weight speed coupling.For efficient flow control, the dimensionless permeability is defined as Darcy number, $\mathrm{Da}=7.86 \times 10-3$ and $\varepsilon=0.95$ (Naito and Fukagata, 2012). (Karthik et al., 2018b). To compute the aerodynamic drag coefficient and acoustic pressure signals, the unsteady information is collected, once the fluid flow attains the statistically steady-state. The flow-induced sound is calculated using the FW-H acoustic analogy (Williams and Hawkings, 1969) with the 2D URANS results as input by using a "correlation length" method (Cox et al., 1998; Liu et al., 2015). The "correlation length" technique presumes that the vortex shedding is totally related over a specific length of the cylinder in the lengthwise course (Casalino and Jacob, 2003). The correlation length that is required in this method can be found experimentally by determining the surface static pressure along the length of the cylinder. In this paper, a correlation length of $6 \mathrm{D}$ is adopted based on the previous experimental data (Porteous et al., 2017; Vickery, 1966). Detailed explanations of the fluid governing equations, acoustic analogy, and correlation length model may be found in previous studies (Casalino and Jacob, 2003; Karthik et al., 2018a; Samion et al., 2016). The CFD simulations have been carried out by implementing the cylinder models in the commercial flow solver ANSYS Fluent (Ansys, 2011), and a MATLAB code (MatLab, 2012) was developed for processing the acoustic pressure data.

\section{RESULTS AND DISCUSSIONS}

The dimensions of the computational domain around the 2D square cylinder are shown in Fig. 2. The uniform fluid stream is normal to the inlet boundary „AB $\mathrm{AB}^{\mathrm{ce}}$, i.e. $\mathrm{x}$-axis is parallel to the incoming velocity $\mathrm{U}$. The origin $(0,0)$ of the coordinate system is positioned at the midpoint of the cylinder. The boundaries „BC $\mathrm{BC}^{\mathrm{ce}}$ and „have zero shear pressure and uniform speed. The outlet limit 'CD' has a zero gauge pressure. The no-slip (wall) condition is assigned on the cylinder surface. The computational domain size is chosen as 31.5D $\times 21 \mathrm{D}$ (Samion et al., 2016).

A near wall resolution of $\mathrm{y}+=1$ has been protected close to the surface for completely resolving the laminar sublayer. Along the peripheral surface of the cylinder, the cells are being spaced equally at $0.02 \mathrm{D}(=\Delta \mathrm{s})$ apart. For numerical calculations, the tempestuous flow trench ought to accomplish a statistically steady state and this happens at around $0.1 \mathrm{~s}$. In all computations, the entire simulation time is $1.1 \mathrm{~s}$ and the

final $0.9 \mathrm{~s}$ (i.e. $=\mathrm{T}$; from $0.2 \mathrm{~s}$ to $1.1 \mathrm{~s}$ ) of time history information is utilized in computing the fluid and acoustic outcomes.

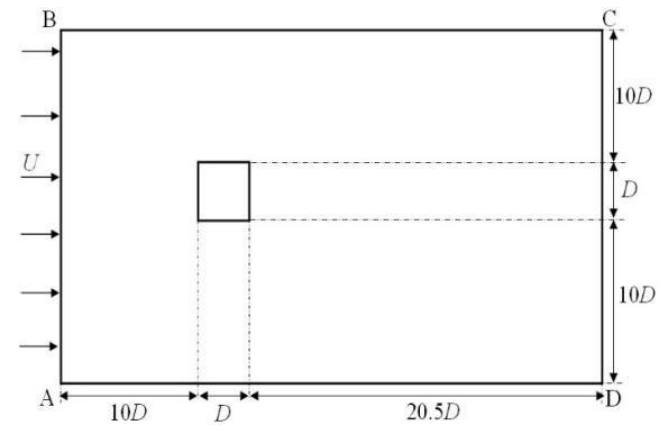

Figure 2: Schematic diagram of the computational domain (not to scale).

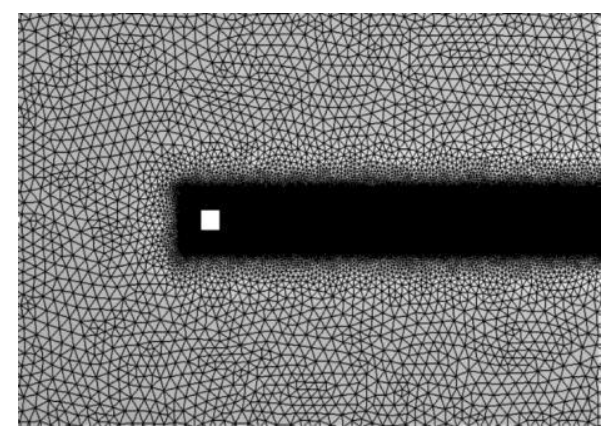

Figure 3 Computational Mesh

The exactness of the SPL computations essentially depends on the precision of the URANS. To validate this solution, the mean aerodynamic drag coefficient (CD,mean), rms lift coefficient (CL,rms) and Strouhal number (St) corresponding to the dominant vortex shedding frequency, computed numerically, are compared with previous studies (Table 1). The CD,mean, CL,rms and St of the cylinder acquired from CFD are in great concurrence with the past investigations (Bosch and Rodi, 1998; Murakami and Mochida, 1995; Park, 1995; Samion et al., 2016; Shimada and Ishihara, 2002; Sohankar, 2006; Tian et al., 2013; Vickery, 1966)

Table 1: comparison of the numerical solution with the literature

\begin{tabular}{|c|c|c|c|}
\hline Method (Author) & $\boldsymbol{C}_{\boldsymbol{D} \text {,mean }}$ & $\boldsymbol{C}_{\boldsymbol{L}, \boldsymbol{r m s}}$ & $\boldsymbol{S t}$ \\
\hline$k-\omega$ SST (Present) & 2.181 & 1.485 & 0.118 \\
\hline $\begin{array}{c}k-\omega \text { SST (Tian et al., } \\
\text { 2013) }\end{array}$ & 2.06 & 1.492 & 0.138 \\
\hline $\begin{array}{c}k-\omega \text { SST (Samion et al., } \\
\text { 2016) }\end{array}$ & 2.1 & 1.43 & 0.126 \\
\hline $\begin{array}{c}k-\varepsilon(\text { Bosch and Rodi, } \\
\text { 1998) }\end{array}$ & 2.108 & 1.012 & 0.146 \\
\hline $\begin{array}{c}k-\varepsilon(\text { Shimada and } \\
\text { Ishihara, 2002) }\end{array}$ & 2.05 & 1.43 & 0.141 \\
\hline $\begin{array}{c}\text { LES (Murakami and } \\
\text { Mochida, 1995) }\end{array}$ & .09 & 1.6 & 0.132 \\
\hline $\begin{array}{c}\text { LES (Sohankar, 2006) } \\
\text { (Socha }\end{array}$ & 2.19 & 1.433 & 0.118 \\
\hline
\end{tabular}




\begin{tabular}{|c|c|c|c|}
\hline $\begin{array}{c}\text { Experiment (Park, } \\
\text { 1995) }\end{array}$ & 2.1 & - & 0.13 \\
\hline $\begin{array}{c}\text { Experiment (Vickery, } \\
\text { 1966) }\end{array}$ & 2.044 & 1.299 & 0.12 \\
\hline $\begin{array}{c}\text { Empirical; Circular } \\
\text { cylinder (Norberg, } \\
\text { 2003) }\end{array}$ & - & 0.5 & 0.188 \\
\hline
\end{tabular}

To assess the precision of the far-field acoustic investigation, the figured flow actuated sound information are approved utilizing trial results (Latorre Iglesias et al., 2016) at $\operatorname{Re}=54,800$. The sound estimations were led in an echo-free wind tunnel on a square cylinder. The PSD of the calculated sound pressure at the receiver location $(0,87.5 \mathrm{D}, 0)$ has been obtained using Welch technique (Dumitran, 2014) adopting Hann window with $50 \%$ overlap of 3 data segments (Oppenheim, 1987).

Figure 4 shows the examination of the registered SPL range with test information (Latorre Iglesias et al., 2016). The figured range concurs with the exploratory range at the important districts and demonstrates a satisfactory match elsewhere. The most essential qualities of this range, explicitly, tonal Strouhal number (for example the Strouhal number related with the pinnacle recurrence of the range, spoken to by St) and the tonal SPL at this recurrence (spoken to by SPLT in $\mathrm{dB}$ ) coordinate exactly with test results as appeared Table 2. This implies the URANS and FW-H strategy used in this examination is fit to foresee the essential highlights of the aero acoustic sound and furthermore has the ability to display extra knowledge through a parametric report. To make clear the sound decrease levels at the recipient area, the OASPL, which is a gauge of the all-out sound vitality of the SPL range is used in this paper.

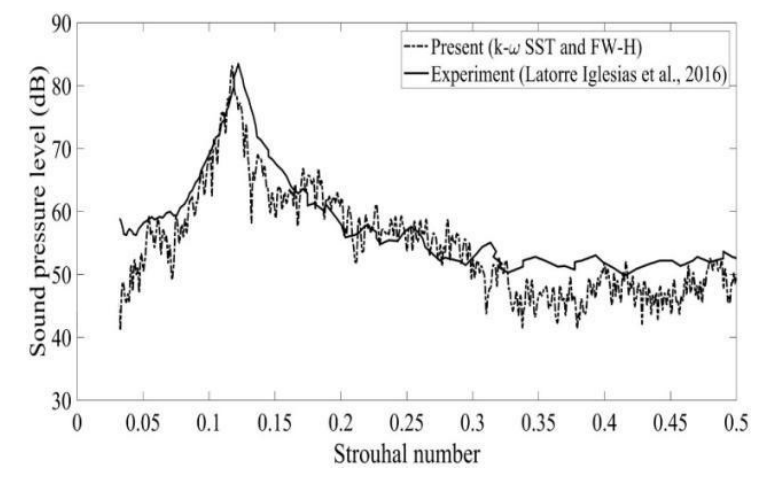

Figure 4: Comparison of the numerical SPL spectrum with the experimental result.

Table 2: Comparison of the calculated sound parameters with experimental results.

\begin{tabular}{|c|c|c|}
\hline Acoustic parameters & Exp. & Num. \\
\hline$S t_{T}$ & 0.122 & 0.118 \\
\hline $\mathrm{SPL}_{\mathrm{T}}(\mathrm{dB})$ & 83.48 & 83.06 \\
\hline
\end{tabular}

Table 3: CD,mean and OASPL of a cylinder with and without porous cover.

\begin{tabular}{|c|c|c|c|c|}
\hline$H / D$ & \multicolumn{2}{|c|}{$C_{D, \text { mean }}$} & \multicolumn{2}{c|}{ OASPL } \\
\hline & CFD & $\begin{array}{c}\text { Reduction } \\
(\%)\end{array}$ & CFD & $\begin{array}{c}\text { Reduction } \\
(\mathrm{dB})\end{array}$ \\
\hline 0 & 2.181 & - & 96.89 & - \\
\hline 0.1 & 1.452 & 33.43 & 93.51 & 3.38 \\
\hline 0.15 & 1.399 & 35.86 & 91.65 & 5.24 \\
\hline 0.2 & 1.361 & 37.62 & 90.02 & 6.87 \\
\hline 0.25 & 1.318 & 39.57 & 89.33 & 7.56 \\
\hline 0.3 & 1.281 & 41.25 & 88.74 & 8.15 \\
\hline 0.35 & 1.340 & 38.54 & 87.47 & 9.42 \\
\hline 0.4 & 1.379 & 36.79 & 87.53 & 9.36 \\
\hline
\end{tabular}

With regards to enhancement, a response surface for both OASPL and CD, mean width permeable thickness as the variable was built. The built RSA models are as per the following:

OASPL $(\mathrm{dB})=(0.15809 \times \mathrm{L} 6)+(0.85074 \times \mathrm{L} 5)-$ $(0.11494 \times \mathrm{L} 4)-(2.2725 \times \mathrm{L} 3)+(0.2507 \times \mathrm{L} 2)-(0.93467 \times \mathrm{L})+$ 89.33

$\mathrm{CD}$, mean $=(-0.057872 \times \mathrm{L} 6)-(0.045085 \times \mathrm{L} 5)+$ $(0.15275 \times \mathrm{L} 4)+(0.13232 \times \mathrm{L} 3)-(0.030074 \times \mathrm{L} 2)-$ $(0.11269 \times \mathrm{L})+1.3$

Where $\mathrm{L}=(\mathrm{H} / \mathrm{D}-0.25) / 0.10801$

Comparing the St (see Table 2) with the St (see Table 1), it is clear that the peak sound frequency takes place at around the dominant vortex shedding frequency, which means the dominant role of vortex shedding on aero acoustic sound generation. So, by amending the vortical flow structures in the cylinder wake, the sound production can be controlled (You et al., 1998) and this is what a cylinder with a porous cover does (Bruneau and Mortazavi,2004).

The R-square and RMSE for these sixth-degree polynomials (Eq. 11 and 12) are given in Table 4. The knee point of the Pareto optimal front (Fig. 6) is found to be $\mathrm{H} / \mathrm{D}=$ 0.3201

In the present work, a square cylinder with a porous cover of non-dimensional thickness $0.1 \mathrm{D}$ to $0.4 \mathrm{D}$ with intervals of $0.05 \mathrm{D}$ is simulated numerically. The instantaneous drag force and flow-induced sound pressure of all the models were numerically computed. Table 3 records the values of $\mathrm{CD}$, mean and OASPL for all cases. It can be noticed that the mean drag force $(\mathrm{CD}$, mean) and flow-induced sound (represented by OASPL) of cylinders with porous are significantly suppressed, with respect to the unmodified cylinder. 
This is due to the increased base pressure of the modified cylinder compared to the unmodified one (Naito and Fukagata, 2012; Zhao and Cheng, 2010) (Fig. 7). The presence of porous cover shows the way to a considerable decrease of the vorticity magnitude (Bruneau and Mortazavi, 2008, 2004), and in turn, reduce flow-induced sound (Liu et al., 2015) (Fig. 8). When a porous cover of $\mathrm{H}=0.35 \mathrm{D}$ is connected to the barrel, the sound outflow and drag constrain lessens by about $9.42 \mathrm{~dB}$ and $38.54 \%$ individually. So also, when a permeable front of $\mathrm{H}=0.3 \mathrm{D}$ is connected to the cylinder sound emanation and drag drive diminish by about $8.15 \mathrm{~dB}$ and $41.25 \%$ individually. Further increment in the $\mathrm{H}$ (> $0.35 \mathrm{D})$ results in higher $\mathrm{CD}$, mean and OASPL. The variety of $\mathrm{CD}$, mean and OASPL with and the corresponding results are given in Table 5 .

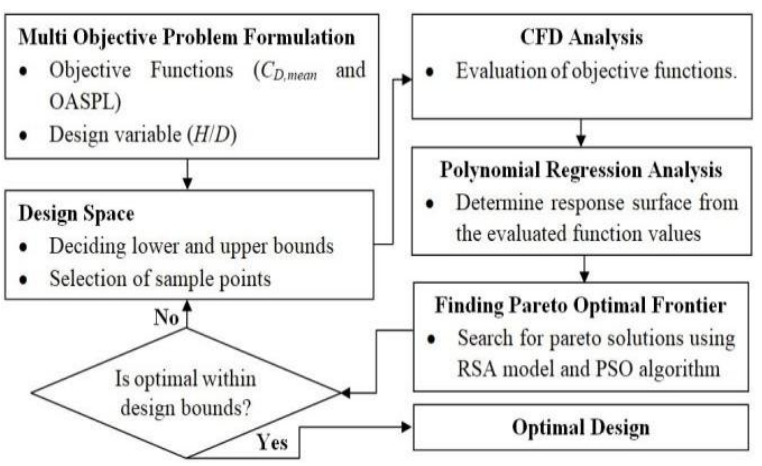

Figure 5: Design methodology

Table 4: Statistical parameters of the RSA model Goodness-of-Fit Statistics CD, mean OASPL R-square 0.990 .99

\begin{tabular}{|c|c|c|}
\hline $\begin{array}{c}\text { Goodness-of-Fit } \\
\text { Statistics }\end{array}$ & $\boldsymbol{C}_{\text {D,mean }}$ & OASPL \\
\hline$R$-square & 0.99 & 0.99 \\
\hline
\end{tabular}

Root mean squared error (RMSE) $9.4405 \times 10-6$, $8.8329 \times 10-5$

Table 5: Results for the ideal setup of the cylinder

\begin{tabular}{|c|c|c|}
\hline $\boldsymbol{H} / \boldsymbol{D}$ & OASPL & $\boldsymbol{C}_{\boldsymbol{D}, \text { mean }}$ \\
\hline 0 & 96.89 & 2.181 \\
\hline $\begin{array}{c}0.3201 \\
(\text { Optimum })\end{array}$ & 88.30 & 1.268 \\
\hline Reduction & $8.59 \mathrm{~dB}$ & $41.86 \%$ \\
\hline
\end{tabular}

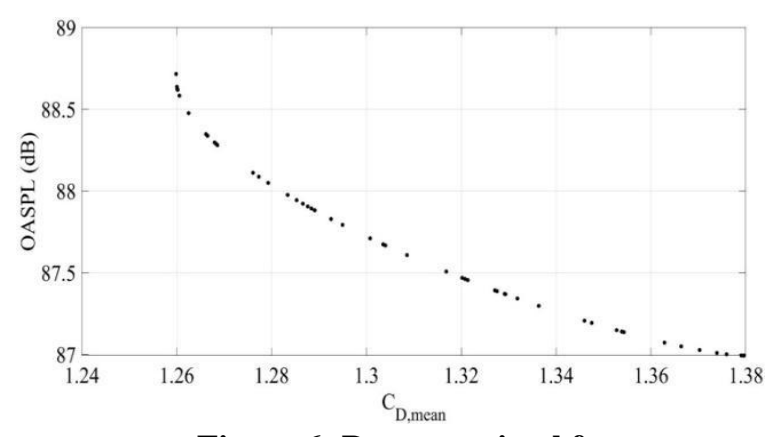

Figure 6: Pareto optimal front

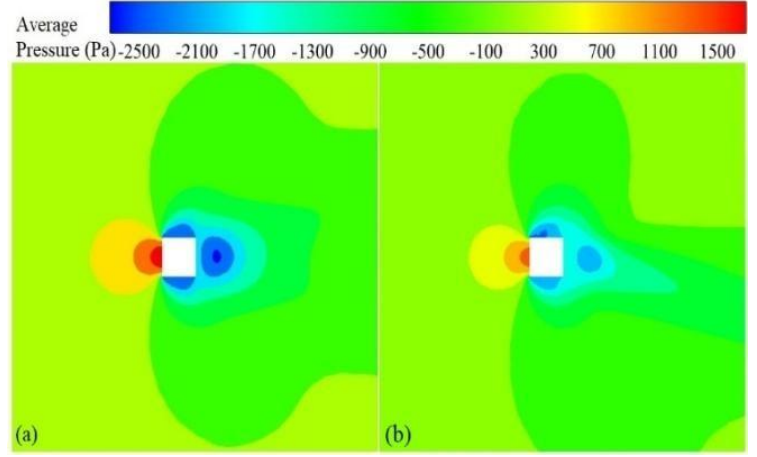

Figure 7: The mean static pressure distributions around square cylinders (a) without and (b) with an optimal porous cover

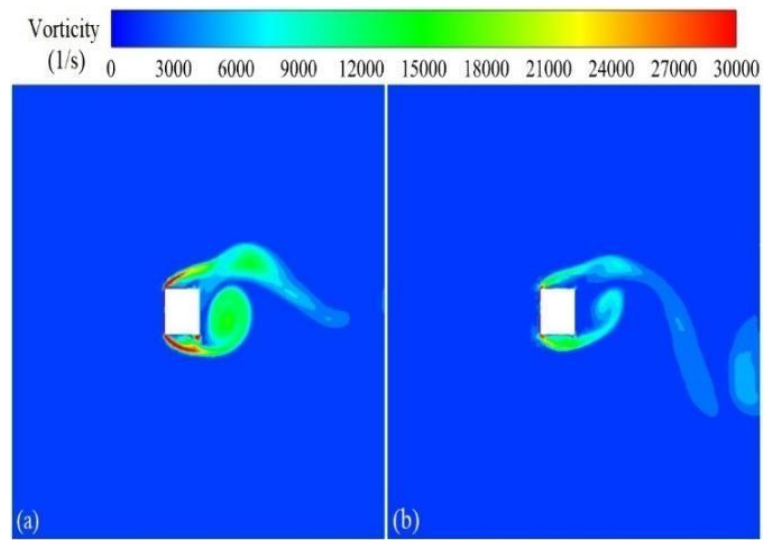

Figure 8: The instantaneous vortices distributions around square cylinders (a) without and (b) with an optimal porous cover.

\section{CONCLUSION}

The use of a square cylinder covered with porous media as a means to reduce drag force in cross-flow is an active area of research. However, the sound that is induced by such flows and the associated sound emission levels has not received much attention. This paper studies aerodynamic and aero acoustic behavior of square cylinders attached with porous cover numerically. The incoming flow field at $\mathrm{Re}=54,800$ has been resolved using the URANS technique, and the far-field acoustic results are computed by means of the FW-H acoustic analogy. The considered cylinder model of optimal porous thickness $\mathrm{H} / \mathrm{D}=0.3201$ show significant drag and sound mitigation. The drag and OASPL reduce by $41.86 \%$ and $8.59 \mathrm{~dB}$, respectively compared to the unmodified cylinder.

\section{REFERENCES}

[1] Anirudh, K., Dhinakaran, S., 2018. On the onset of vortex shedding past a two-dimensional porous square cylinder. Journal of Wind Engineering and Industrial Aerodynamics. https://doi.org/10.1016/j.jweia.2018.03.004 Ansys, I., 2011. ANSYS FLUENT User "e s Guide 15317, 2498.

[2] Babu, V., Narasimhan, A., 2010. Investigation of vortex shedding behind a porous square cylinder using lattice Boltzmann method. Physics of Fluids. https://doi.org/10.1063/1.3407667

[3] Bhattacharyya, S., Singh, A.K., 2011. Reduction in drag and vortex shedding frequency through porous sheath around a circular cylinder. International Journal for Numerical Methods in Fluids. https://doi.org/10.1002/fld.2210

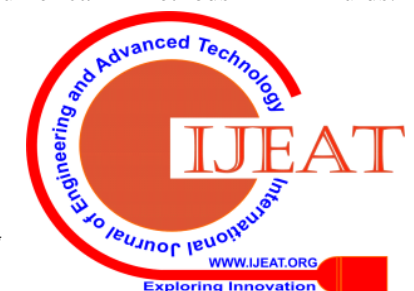


[4] Bosch, G., Rodi, W., 1998. Simulation of vortex shedding past a square cylinder with different turbulence models. International Journal for Numerical Methods in Fluids. https://doi.org/10.1002/(SICI)10970363(19980930)28:4<601::AID-FLD732>3.0.CO;2-F

[5] Bruneau, C.H., Mortazavi, I., 2008. Numerical modeling and passive flow control using porous media. Computers and Fluids 37, 488-498. https://doi.org/10.1016/j.compfluid.2007.07.001

[6] Bruneau, C.H., Mortazavi, I., 2004. Passive control of the flow around a square cylinder using porous media. International Journal for Numerical Methods in Fluids 433, 415-433. https://doi.org/10.1002/fld.756

[7] Casalino, D., Jacob, M., 2003. Prediction of aerodynamic sound from circular rods via spanwise statistical modeling. Journal of Sound and $\begin{array}{lll}\text { Vibration } & 262 \text { 815-844. }\end{array}$ https://doi.org/10.1016/S0022-460X(02)01136-7

[8] Chauhan, M.K., Dutta, S., More, B.S., Gandhi, B.K., 2018. Experimental investigation of flow over a square cylinder with an attached splitter plate at intermediate Reynolds number. Journal of Fluids and Structures. https://doi.org/10.1016/j.jfluidstructs.2017.10.012

[9] Cox, J.S., Brentner, K.S., Rumsey, C.L., 1998. Computation of vortex shedding and radiated sound for a circular cylinder: Subcritical to transcritical Reynolds numbers. Theoretical and Computational Fluid Dynamics 12, 233-253. https://doi.org/10.1007/s001620050108

[10]De, S.S., Ghosh, A.K., 1989. An approximate solution of Poisson "es equation for semiconductor device modeling. Solid State Electronics 32, 517-519. https://doi.org/10.1016/j.jsv.2011.11.016

[11]Devinant, P., Laverne, T., Hureau, J., 2002. Experimental study of wind-turbine airfoil aerodynamics in high turbulence. Journal of Wind Engineering and Industrial Aerodynamics 90, 689-707. https://doi.org/10.1016/S0167-6105(02)00162-9

[12] Dumitran, A., 2014. Între logos şieikon. Uneseudespreicoana, românişiprotestantismÎntransilvaniasecolului al XVII-LEA. AnnalesUniversitatisApulensis. Series Historica 18, 115-152. https://doi.org/10.1109/TAU.1967.1161901

[13] Geyer, T.F., Sarradj, E., 2016. Circular cylinders with soft porous cover for flow noise reduction. Experiments in Fluids 57, 1-16. https://doi.org/10.1007/s00348-016-2119-7

[14] Gloerfelt, X., Pérot, F., Bailly, C., Juvé, D., 2005. Flow-induced cylinder noise formulated as a diffraction problem for low Mach numbers. Journal of Sound and Vibration 287, 129-151. https://doi.org/10.1016/j.jsv.2004.10.047

[15] Guo, L., Zhang, X., He, G., 2016. Large-eddy simulation of circular cylinder flow at subcritical Reynolds number: Turbulent wake andsound radiation. Acta Mechanica Sinica/ Lixue Xuebao

32, 1-11. https://doi.org/10.1007/s10409-015-0528-0

16] Inoue, O., Hatakeyama, N., 2002. Sound generation by a twodimensional circular cylinder in a uniform flow. Journal of Fluid Mechanics 471 , 285-314. https://doi.org/10.1017/S0022112002002124

[17] Jue, T.C., 2004. Numerical analysis of vortex shedding behind a porous square cylinder. International Journal of Numerical Methods for Heat and Fluid Flow. https://doi.org/10.1108/09615530410539964

[18] Karthik, K., Vengadesan, S., Bhattacharyya, S.K., 2018a. Prediction of flow-induced sound generated by cross-flow past finite length circular cylinders. The Journal of the Acoustical Society of America 143, 260-270. https://doi.org/10.1121/1.5021243

[19] Karthik, K., Vishnu, M., Vengadesan, S., Bhattacharyya, S.K., 2018 b. Optimization of bluff bodies for aerodynamic drag and sound reduction using CFD analysis. Journal of Wind Engineering and Industrial Aerodynamics 174 ,

$133-140$. https://doi.org/10.1016/j.jweia.2017.12.029

[20] Kaviani, H.R., Nejat, A., 2017. Aerodynamic noise prediction of an MW-class HAWT using shear wind profile. Journal of Wind Engineering and Industrial Aerodynamics

168, 164-176. https://doi.org/10.1016/j.jweia.2017.06.003

[21] Khalighi, Y., Mani, A., Ham, F., Moin, P., 2010. Prediction of Sound Generated by Complex Flows at Low Mach Numbers. AIAA Journal 48, 306-316. https://doi.org/10.2514/1.42583

[22] Khorrami, M.R., Choudhari, M.M., Lockard, D.P., Jenkins, L.N., Mcginley, C.B., 2007. Unsteady Flowfield Around Tandem Cylinders as Prototype Component Interaction in Airframe Noise. AIAA Journal. https://doi.org/10.2514/1.23690

[23] King, W.F., Pfizenmaier, E., 2009. An experimental study of sound generated by flows around cylinders of the different cross-section. Journal of Sound and Vibration 328, 318-337. https://doi.org/10.1016/j.jsv.2009.07.034

[24] Kurbatskii, K.A., Mankbadi, R.R., 2004. Review of computational aeroacoustics algorithms. International Journal of Computational Fluid Dynamics. https://doi.org/10.1080/10618560410001673542

[25]Latorre Iglesias, E., Thompson, D.J., Smith, M.G., 2016. Experimental study of the aerodynamic noise radiated by cylinders with different cross- sections and yaw angles. Journal of Sound and Vibration 361, 108-129. https://doi.org/10.1016/j.jsv.2015.09.044

[26]Leonard, B.P., 1979. A stable and accurate convective modeling procedure based on quadratic upstream interpolation. Computer Methods in Applied Mechanics and Engineering. https://doi.org/10.1016/0045- 7825(79)90034-3

[27]Liu, H., Azarpeyvand, M., Wei, J., Qu, Z., 2015. Tandem cylinder aerodynamic sound control using a porous coating. Journal of Sound and Vibration 334, 190-201. https://doi.org/10.1016/j.jsv.2014.09.013

[28]Liu, H., Wei, J., Qu, Z., 2013. The Interaction of Porous Material Coating with the Near Wake of Bluff Body. Journal of Fluids Engineering 136, 021302. https://doi.org/10.1115/1.4026071

[29] MatLab, M., 2012. The Language of Technical Computing. The MathWorks, Inc. http://www. MathWorks.com. https://doi.org/10.1007/s10766-008-0082-5

[30] Menter, F.R., 1994. Two-equation eddy-viscosity turbulence models forengineering applications. Journal. https://doi.org/10.2514/3.12149

[31] Moreau, D.J., Doolan, C.J., 2013. Flow-Induced Sound of WallMounted Finite Length Cylinders. AIAA Journal 51, 2493-2502. https://doi.org/10.2514/1.J052391

[32] Moreau, D.J., Prime, Z., Porteous, R., Doolan, C.J., Valeau, V., 2014. Flow-induced noise of a wall-mounted finite airfoil at low-to-moderate Reynolds number. Journal of Sound and Vibration 333, 6924-6941. https://doi.org/10.1016/j.jsv.2014.08.005

[33] Murakami, S., Mochida, A., 1995. On turbulent vortex shedding flow past 2D square cylinder predicted by CFD. Journal of Wind Engineering and Industrial Aerodynamics. https://doi.org/10.1016/0167-6105 (94)00043-D

[34] Naito, H., Fukagata, K., 2012. Numerical simulation of flow around a circular cylinder having a porous surface. Physics of Fluids 24 https://doi.org/10.1063/1.4767534

[35] Norberg, C., 2003. Fluctuating lift on a circular cylinder: Review and new measurements. Journal of Fluids and Structures 17, 57-96. https://doi.org/10.1016/S0889-9746 (02)00099-3

[36] Oppenheim, A. V, 1987. The Discrete-Time Signal Processing. Book. Park, J.H., 1995. A laser-Doppler velocimetry study of ensemble-averaged characteristics of the turbulent near wake of a square cylinder. Journal of Fluid Mechanics 304 285-319. https://doi.org/10.1017/S0022112095004435

[37] Porteous, R., Moreau, D.J., Doolan, C.J., 2017. The aeroacoustics of finite wall-mounted square cylinders. Journal of Fluid Mechanics 832 , 287- 328. https://doi.org/10.1017/jfm.2017.682

[38] Purohit, A., Darpe, A.K., Singh, S.P., 2014. A study on aerodynamic sound from an externally excited flexible structure in flow. Computers and $\quad$ Fluids 103 https://doi.org/10.1016/j.compfluid.2014.07.010

[39] Rienstra, S.W., Sijtsma, P., 2018. Review of "Aeroacoustics of low Mach number flows Fundamentals, Analysis and Measurement," Journal of Sound and Vibration. https://doi.org/10.1016/j.jsv.2018.06.010

[40]Rong, F.M., Guo, Z.L., Lu, J.H., Shi, B.C., 2011. Numerical simulation of the flow around a porous covering square cylinder in a channel via lattice Boltzmann method. International Journal for Numerical Methods in Fluids. https://doi.org/10.1002/fld.2237

[41] Salimi, M.R., TaeibiRahni, M., Jam, F., 2015. Pore-scale simulation of fluid flow passing over a porously covered square cylinder located at the middle of a channel, using a hybrid MRT-LBM???FVM approach. Theoretical and Computational Fluid Dynamics 29, 171-191. https://doi.org/10.1007/s00162-015-0347-8

[42] Samion, S.R.L., Ali, M.S.M., Abu, A., Doolan, C.J., Porteous, R.Z.Y 2016. Aerodynamic sound from a square cylinder with a downstream wedge. Aerospace Science and Technology 53, 85-94. https://doi.org/10.1016/j.ast.2016.03.007

[43] Shimada, K., Ishihara, T., 2002. Application of a modified k- $\varepsilon$ model to the prediction of aerodynamic characteristics of rectangular cross-section cylinders. Journal of Fluids and Structures. https://doi.org/10.1006/jfls.2001.0433 
[44] Sohankar, A., 2006. Flow over a bluff body from moderate to high Reynolds numbers using large eddy simulation. Computers and Fluids 35, 1154-1168. https://doi.org/10.1016/j.compfluid.2005.05.007

[45] Sueki, T., Takaishi, T., Ikeda, M., Arai, N., 2010. Application of porous material to reduce aerodynamic sound from bluff bodies. Fluid Dynamics Research https://doi.org/10.1088/0169-5983/42/1/015004

[46] Sukri Mat Ali, M., Doolan, C.J., Wheatley, V., 2011. The sound generated by a square cylinder with a splitter plate at low Reynolds number. Journal of Sound and Vibration 330, 3620-3635. https://doi.org/10.1016/j.jsv.2011.03.008

[47] Talotte, C., 2000. Aerodynamic noise: a critical survey. Journal of Sound and Vibration 231, 549-562. https://doi.org/10.1006/jsvi.1999.2544

[48] Tam, C.K.W., 2006. Recent advances in computational aeroacoustics. Dynamics Research 38 , 591-615. https://doi.org/10.1016/j.fluiddyn.2006.03.006

[49] Tian, X., Ong, M.C., Yang, J., Myrhaug, D., 2013. Unsteady RANS simulations of the flow around rectangular cylinders with different aspect ratios. Ocean Engineering. https://doi.org/10.1016/j.oceaneng.2012.10.013

[50] Vickery, B.J., 1966. Fluctuating lift and drag on a long cylinder of the square cross-section in a smooth and in a turbulent stream. Journal of Fluid Mechanics 25, 481-494. https://doi.org/10.1017/S002211206600020X

[51] Vilela de Abreu, R., Jansson, N., Hoffman, J., 2016. Computation of aeroacoustic sources for a Gulfstream G550 nose landing gear model using adaptive FEM. Computers and Fluids 124, 136-146. https://doi.org/10.1016/j.compfluid.2015.10.017

[52] Wang, M., Freund, J.B., Lele, S.K., 2006. Computational Prediction of Flow-Generated Sound. Annual Review of Fluid Mechanics 38, 483-512. https://doi.org/10.1146/annurev.fluid.38.050304.092036

[53] Wilcox, D.C.D.C.D.C., 2006. Turbulence Modeling for CFD: Text. Aiaa. https://doi.org/0963605151

\section{AUTHORS PROFILE}

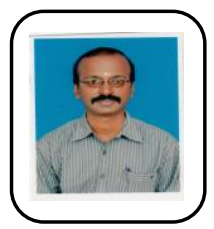

Dr. S. Jeyakumar, working as Professor in Aeronautical Engineering, Kalasalingam Academy of Research and Education. The author has published papers in the areas of high-speed flow mixing and combustion, cavity flow, dual combustion ramjet engine.

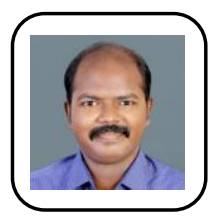

K. Karthik, working as Assistant Professor in Aeronautical Engineering, Kalasalingam Academy of Research and Education. The author has published papers in the areas of CFD, and aero acoustics.

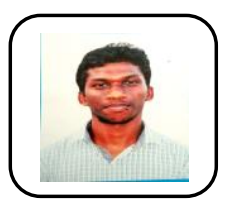

Alexander M, was a student of Kalasalingam Academy of Research and Education and is currently working as production engineer in Chennai, India 